\title{
Successful Fractional Exhaled Nitric Oxide Measurements with NIOX VERO using 6- and 10-s Exhalation Modes in Children with Asthma Aged 4-10 Years: A Randomized Study
}

\author{
Glenn Crater · Kathy Rickard · Neal Jain
}

Received: November 10, 2016 / Published online: February 6, 2017

(C) The Author(s) 2017. This article is published with open access at Springerlink.com

\begin{abstract}
Introduction: Fractional exhaled nitric oxide (FeNO) is a valuable tool for measuring allergic airway inflammation in children with asthma, particularly in those for whom other tests are difficult to perform. The use of a 6-s exhalation time (6-s mode) rather than $10 \mathrm{~s}$ (10-s mode) used for adults is in line with current recommendations, making FeNO a feasible option for younger children. However, sparse data are available that demonstrate the agreement between exhalation modes in young children.

Methods: This study assessed the degree of agreement of FeNO measured using the 6- and 10 -s modes in young children (6-10 years) with asthma and the feasibility of use in younger children (4-5 years) with asthma using the
\end{abstract}

Enhanced content To view enhanced content for this article go to http://www.medengine.com/Redeem/ 5687F060783C4983.

Electronic supplementary material The online version of this article (doi:10.1007/s41030-017-0028-4) contains supplementary material, which is available to authorized users.

G. Crater $\cdot$ K. Rickard $(\bowtie)$

Circassia Pharmaceuticals Inc, Morrisville, NC, USA

e-mail: kathy.rickard@circassia.com

N. Jain

Arizona Allergy and Immunology Research, Gilbert, AZ, USA
NIOX VERO $^{\circledR}$ analyzer. Enrolment was stratified so that 15 subjects had FeNO $>35$ ppb and 35 had FeNO $<35$ ppb.

Results: For subjects aged 6-10 years, agreement and repeatability was shown with mean observed FeNO measurements of $34.36 \mathrm{ppb}$ (6-s mode) and $33.35 \mathrm{ppb}$ (10-s mode) and paired differences were centered close to 0 (median 0.50). In the 4-5-year age group, ten subjects had a valid 6-s mode FeNO result (mean value, $12.6 \mathrm{ppb}$ ) of which seven (70\%) also had a valid 10 -s mode FeNO result (mean value, $10.6 \mathrm{ppb}$ ) with good correspondence in FeNO results between the modes.

Conclusions: Children aged 4-10 years can successfully perform FeNO measurements using the NIOX $\mathrm{VERO}^{\circledR}$ analyzer in the 6-s or the 10-s modes. FeNO measurements were repeatable and consistent with a high degree of agreement between the two modes in children aged 6-10 years. Younger children (4-5 years) also successfully performed FeNO measurements using both modes and were more successful using the 6-s mode. Thus, in young children, successful FeNO measurements can be obtained, providing physicians with important information in this age group to aid in the diagnosis and treatment of asthma.

Funding: Aerocrine Inc (now Circassia Pharmaceuticals Inc). 
Keywords: Asthma; Children; Exhalation modes; NIOX VERO; Nitric oxide; Randomized; Repeatability

\section{INTRODUCTION}

Fractional exhaled nitric oxide (FeNO) is a valuable tool for measuring allergic airway inflammation in patients with asthma. It is a direct marker of T-helper type 2 (Th2)-driven inflammation in the airways and can assist in the diagnosis of asthma [1], help identify patients who will respond to inhaled corticosteroids (ICS) [2], and predict risk of asthma worsening [3]. When used to regularly monitor patients, FeNO has been shown to reduce exacerbations of both in adults $[4,5]$ and in pediatric patients $[6,7]$. FeNO may also predict the development of persistent asthma, so methods to measure FeNO in younger patients is important [8-11].

Measuring FeNO is particularly valuable in young children for whom other tests are difficult to perform. Obtaining reliable spirometry measurements can be difficult, and neither this nor other routinely available tests, such as the Childhood Asthma Control Test (C-ACT), provide information about airway inflammation [1]. In contrast, FeNO measurements are easy, quick to perform in the clinic, and reproducible [8-10]. In addition, FeNO testing uses a different respiratory maneuver to the other assessments, which does not involve a forced vital capacity maneuver. This makes it easier for children, and especially young children, to perform, therefore aiding cooperation [11].

However, the use of FeNO in children has its own challenges [11]. Children are sometimes unable to exhale for $10 \mathrm{~s}$ to meet the recommended time for a measurement as approved by the FDA, and this can make monitoring children difficult.

NIOX VERO ${ }^{\circledR}$ (Fig. 1) has been recently approved as the next-generation FeNO analyzer to NIOX $\mathrm{MINO}^{\circledR}$ and is now available for clinical use in the European Union (EU), United States of America (USA), Japan, China, and other major markets. Patients aged 7 years

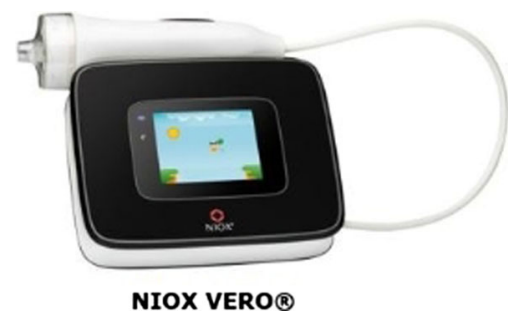

Fig. 1 An illustration of the NIOX Vero ${ }^{\circledR}$ analyzer

and older can use NIOX VERO ${ }^{\circledR}$ and the device may be suitable for some children aged from 4 years providing they are able to cooperate with the procedure. NIOX VERO ${ }^{\circledR}$ may help to overcome the challenges faced when measuring FeNO in younger children because it enables physicians to use an exhalation time of either $10 \mathrm{~s}$ (10-s mode) or $6 \mathrm{~s}$ (6-s mode) once the latter is approved by the FDA (note: NIOX VERO ${ }^{\circledR} 6$-s mode is available in the EU).

Current guidelines require exhalation of at least $4 \mathrm{~s}$ for children younger than 12 years; longer than $6 \mathrm{~s}$ is acceptable for children over 12 years of age [12]. The use of the 6-s mode to measure FeNO in children rather than the 10-s mode used for adults is in line with these recommendations and makes FeNO a feasible option for younger children.

Sparse data are available that demonstrate the agreement (or comparability) between the 6 -s and 10-s modes for the measurement of FeNO in children aged $6-10$ years. The NIOX $\mathrm{VERO}^{\circledR}$ has the capability of measuring FeNO using both the 6-s and 10-s modes. This study assessed the degree of agreement of FeNO measured using the 6-s and 10-s modes in young children (6-10 years) and assessed the feasibility of use in younger children aged $4-5$ years.

\section{METHODS}

\section{Study Design}

This was a randomized, single-visit, point-of-care, clinical validation study conducted at a single study center in the USA on October 12, 2013. The study was approved by the local Institutional Review Board (IRB; 
Sterling IRB, Atlanta, GA, USA) and was conducted in compliance with Good Clinical Practice and the Declaration of Helsinki.

\section{Subjects}

Males and females aged 4-10 years were enrolled who had physician-diagnosed asthma and whose primary language was English. In the 4-5 years age group, ten subjects were planned; in the 6-10 years age group, enrolment was planned such that 15 subjects were to have FeNO above $35 \mathrm{ppb}$ and 35 subjects were to have FeNO below $35 \mathrm{ppb}$. Excluded subjects had any other pulmonary disease, acute asthma symptoms, respiratory illness or sinusitis; had not refrained from taking food or drink (other than water) within 15 min before the FeNO measurement, or had done strenuous exercise within $1 \mathrm{~h}$ of the FeNO assessment. Informed consent was obtained from each subject's legally authorized representative before being included in the study.

\section{Device and Training}

After enrolment, an operator demonstrated the use of the NIOX VERO ${ }^{\circledR}$ device to each subject. Under the direction of an operator, each subject was allowed up to ten attempts to perform a single valid FeNO measurement with a rest break of $30 \mathrm{~s}$ or less between measurements. A measurement was considered valid if the FeNO value was displayed on the device. If after ten attempts the subject was unable to perform a valid measurement, the subject was discharged from the study. To avoid bias, subjects were randomized to two measurements taken using the 6-s mode followed by two measurements using the 10-s mode or vice versa.

Subjects aged 4 and 5 years were not randomized and were included in the study to assess their ability to successfully complete FeNO measurements as evidenced by display of a FeNO value on the NIOX VERO ${ }^{\circledR}$ device using both the 6-s and 10-s modes. Subjects in this age group performed one FeNO measurement using the 6-s mode and following successful completion of this, they attempted to perform a measurement using the 10-s mode.

\section{Assessments}

NIOX VERO ${ }^{\circledR}$ was used according to the appropriate user manual [13]. In brief, each subject was instructed to breathe out fully to empty their lungs, close their lips around the mouthpiece on the filter to prevent air leakage, and then inhale deeply to total lung capacity. A graphic (in the shape of a cloud) on the device's screen moves as the subject inhales. Each subject then exhaled slowly through the filter while keeping the cloud within the limits shown by the white lines on the screen. Subjects exhaled until the cloud moved past the flag shown on the right-hand side of the screen. Occurrences of adverse events (AE) or serious injuries were monitored. A worsening of asthma was not considered an AE unless this event met the criteria for serious injury.

\section{Statistical Methods}

The primary objective was to assess the estimated bias at the $35 \mathrm{ppb}$ cut-off using weighted Deming regression analysis, which modeled the observed 6-s mode FeNO measurement as a function of the 10 -s mode FeNO measurement. The mean value of the replicate FeNO measurements for each mode was used for the analyses. Values of FeNO

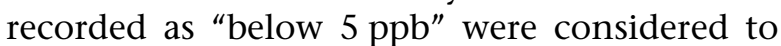

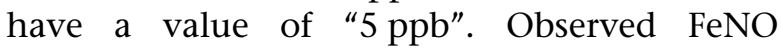
measurements collected using the 6-s mode were graphically compared to the corresponding FeNO collected using the 10-s mode.

Agreement was assessed using a weighted Deming regression analysis of observed data and Bland-Altman plots [14]; Bland-Altman graphs plotted the paired difference (6-s mode - 10-s mode) against the mean FeNO results for the average 6-s and average 10-s modes to compare the difference of test results between the methods. The acceptable bias at the $35 \mathrm{ppb}$ cut-off value was pre-specified to be $7 \%$. 
Average bias was assessed based on the weighted Deming regression across the entire range of observed FeNO test values. FeNO values measured using the 10-s mode were compared with those measured using the 6-s mode to evaluate the percentage of subjects within the tolerance limits.

A sample size of 50 subjects aged 6-10 years was chosen based on the NCCLS EP9-A2 guidance document [15], which recommends a sample size of at least 40 subjects. For this study, the number was increased to 50 to allow for missing data or invalid results (up to 20\%). All statistical analyses were performed using SAS Software, release V9.2 (SAS Institute, Cary, NC, USA).

Data Availability The datasets generated during and/or analyzed during the current study are not publicly available due the fact that it did not fall under the FDAAA 2007 requirements to publicly disclose the data, but data are available from the corresponding author on reasonable request.

\section{RESULTS}

\section{Subjects}

Overall, 65 subjects ( 53 subjects aged $6-10$ years and 12 subjects aged $4-5$ years) were enrolled and completed the study (Table 1). Three subjects (two subjects aged 4-5 years and one subject aged 6-10 years) did not have valid FeNO assessments within ten attempts; $48(90.6 \%)$ aged $6-10$ years had at least one evaluable FeNO measurement in both the 6-s and 10-s modes and were considered the Evaluable Population; $45(84.9 \%)$ aged 6-10 years had two valid observations during both the 6-s and 10-s modes. In the 6-10 years age group, the mean number of attempts at performing the FeNO measurement was 6.17

Table 1 Demographics for all subjects and for those in the sub-groups aged 6-10 years and 4-5 years

\begin{tabular}{llll}
\hline & Age group (years) & \multicolumn{2}{l}{ Total } \\
\cline { 2 - 4 } & $\mathbf{4 - 5}$ & $\mathbf{6 - 1 0}$ & 65 \\
\hline Number of subjects & 12 & 53 & $7.4(1.89)$ \\
Mean age (standard deviation), years & $4.4(0.51)$ & $8.1(1.35)$ & 4,10 \\
Minimum, maximum & 4,5 & 6,10 & $45(69.2)$ \\
Sex, $n$ (\%), male & $7(58.3)$ & $38(71.7)$ & $15(23.1)$ \\
Ethnicity, $n$ (\%) & & & $49(75.4)$ \\
Hispanic or Latino & $4(33.3)$ & $11(20.8)$ & $1(1.5)$ \\
Not Hispanic or Latino & $7(58.3)$ & $42(79.2)$ & $1(1.5)$ \\
Not reported & $1(8.3)$ & 0 & $2(3.1)$ \\
Race, $n$ (\%) & & $1(1.9)$ & $8(12.3)$ \\
American Indian & 0 & $2(3.8)$ & $52(80.0)$ \\
Asian & 0 & $6(11.3)$ & $2(3.1)$ \\
Black or African American & $2(16.7)$ & $43(81.1)$ & $127.9(12.12)$ \\
White & $9(75.0)$ & $1(1.9)$ & 103,155 \\
Other & $1(8.3)$ & $131.5(10.16)$ & 110,155 \\
Mean height, cm (standard deviation) & $112.0(5.97)$ & 103,122 & \\
Minimum, maximum & &
\end{tabular}


(range, 4-10), In the 4-5 years age group, the mean number of attempts at performing the FeNO measurement was 7.92 (range, 2-10).

No AEs or serious injuries were reported.

\section{6-10-Year-Olds}

\section{Agreement Between Exhalation Modes}

Randomization sequences of the assessments or replicate order did not show a significant influence on the measurement. The mean observed FeNO measurements were similar across the randomization sequence and replicate for both modes with overall means of $34.36 \mathrm{ppb}$ (6-s mode) and $33.35 \mathrm{ppb}$ (10-s mode) (Table 2). The 10-s to 6-s randomization sequence group had means that were slightly larger on every comparison; however, the medians for both modes were similar in both randomization sequences (Supplementary Table 1). The difference occurred because two subjects had observed FeNO results above $100 \mathrm{ppb}$ and both appeared in the 10-s to 6-s sequence.

No outliers were identified in relation to observed FeNO results when investigated as a within-method or between-method outlier [15]. Paired differences in average FeNO results ranged from -11.0 to $13.0 \mathrm{ppb}$ and were centered close to 0 (mean $1.01 \pm 4.59$; median 0.50 ).

Weighted Deming regression analysis showed no evidence of systematic bias in measurements between the 6-s and 10-s modes because the estimated intercept was $-0.564 \mathrm{ppb}$, which is not significantly different from $0(p=0.3642)$ (Fig. 2$)$, and the estimated slope was 1.057 and not significantly different from $1(p=0.0912)$.

Average bias of the 6-s mode predicted from the 10-s mode, expressed as a percentage of the 10 -s mode, was low (2.7\%) across the full range of observed FeNO results (6.0-129.0 ppb). The absolute estimated bias at the $35 \mathrm{ppb}$ cut-off value (1.43) was significantly below the pre-specified limit of $7(p<0.0001)$. The $95 \% \mathrm{CI}$ around the bias contained $0(-0.18$ to 03.05) indicating no bias. The upper bound of the $\mathrm{CI}$ on the estimated bias at $35 \mathrm{ppb}$ was $8.7 \%$ of the cut-off value, suggesting bias well below the pre-specified cut-off of $20 \%$.

An even spread of paired differences in average FeNO results was seen between the exhalation modes with larger differences only noted for two subjects with the largest observed FeNO results (Fig. 3). Data points tended to be scattered above the reference line than below and, overall, the plot showed no evidence of any systematic bias between the exhalation modes.

\section{Repeatability}

When using either the 6-s or 10-s modes, the FeNO measurements were repeatable. The mean intra-subject standard deviation was slightly higher for the 10-s mode compared to that of the 6 -s mode ( 1.776 versus 1.414 ), but the median values were the same (0.707). Our data provided evidence that there was a similar degree of repeatability within the 6-s and 10-s modes given that the median paired difference was 0 and there was no statistically significant difference noted $(p=0.3090)$.

Table 2 Observed average fractional exhaled nitric oxide (FeNO) results by exhalation mode and the paired intra-subject differences $(6 s-10 s)$ in average FeNO between modes (evaluation population)

\begin{tabular}{|c|c|c|c|}
\hline & \multicolumn{2}{|c|}{ Exhalation mode } & \multirow{2}{*}{$\begin{array}{l}\text { Paired difference } \\
(6 s-10 s)\end{array}$} \\
\hline & $\overline{6 s}$ & $10 \mathrm{~s}$ & \\
\hline $\begin{array}{l}\text { Number of subjects who successfully } \\
\text { completed } \geq 1 \text { measurement }\end{array}$ & 48 & 48 & 48 \\
\hline Mean FeNO (ppb) & $34.36(25.202)$ & $33.35(24.507)$ & $1.01(4.587)$ \\
\hline Median FeNO (ppb) & 28.00 & 31.25 & 0.50 \\
\hline Minimum, maximum & $5.5,114.5$ & $6.5,120.0$ & $-11.0,13.0$ \\
\hline
\end{tabular}

$\mathrm{FeNO}$ fractional exhaled nitric oxide 


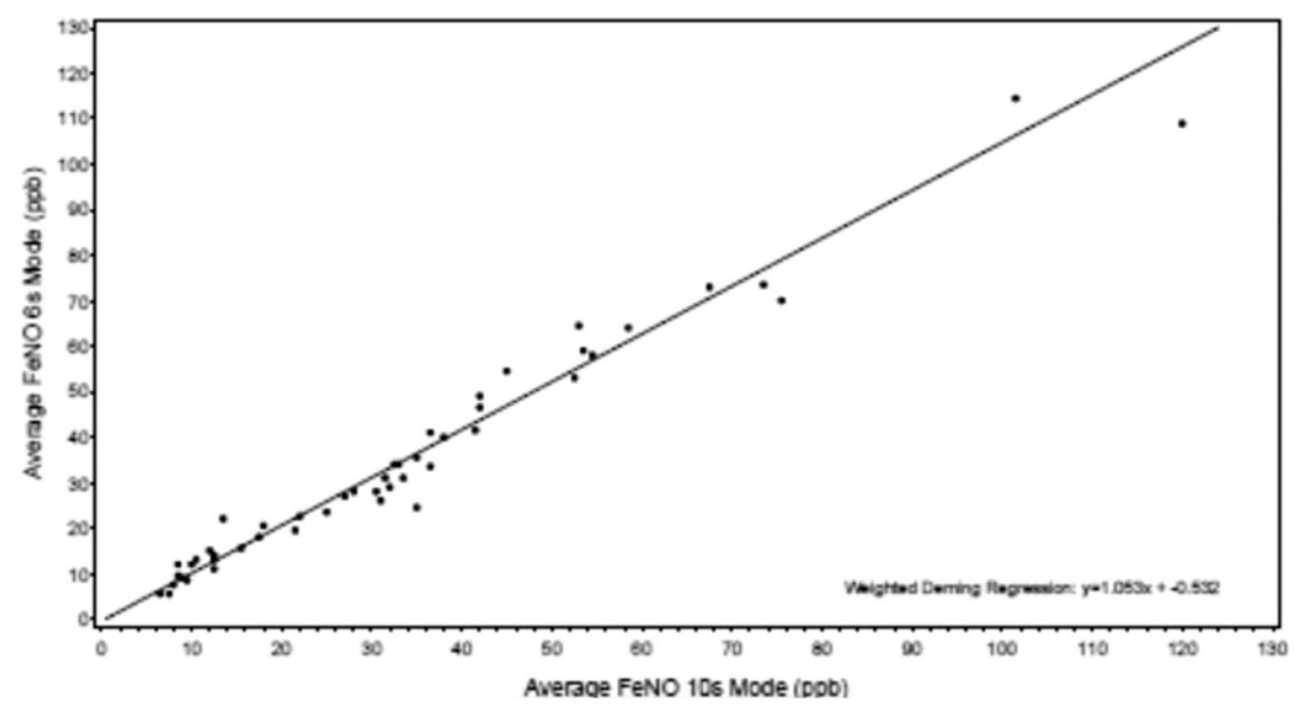

Fig. 2 Weighted Deming regression analysis plot of observed fractional exhaled nitric oxide (FeNO) results for each of the replicate pairs, showing agreement between the FeNO measurements from the 6-s exhalation mode with those obtained using the 10-s exhalation mode for subjects aged 6-10 years (evaluation population)

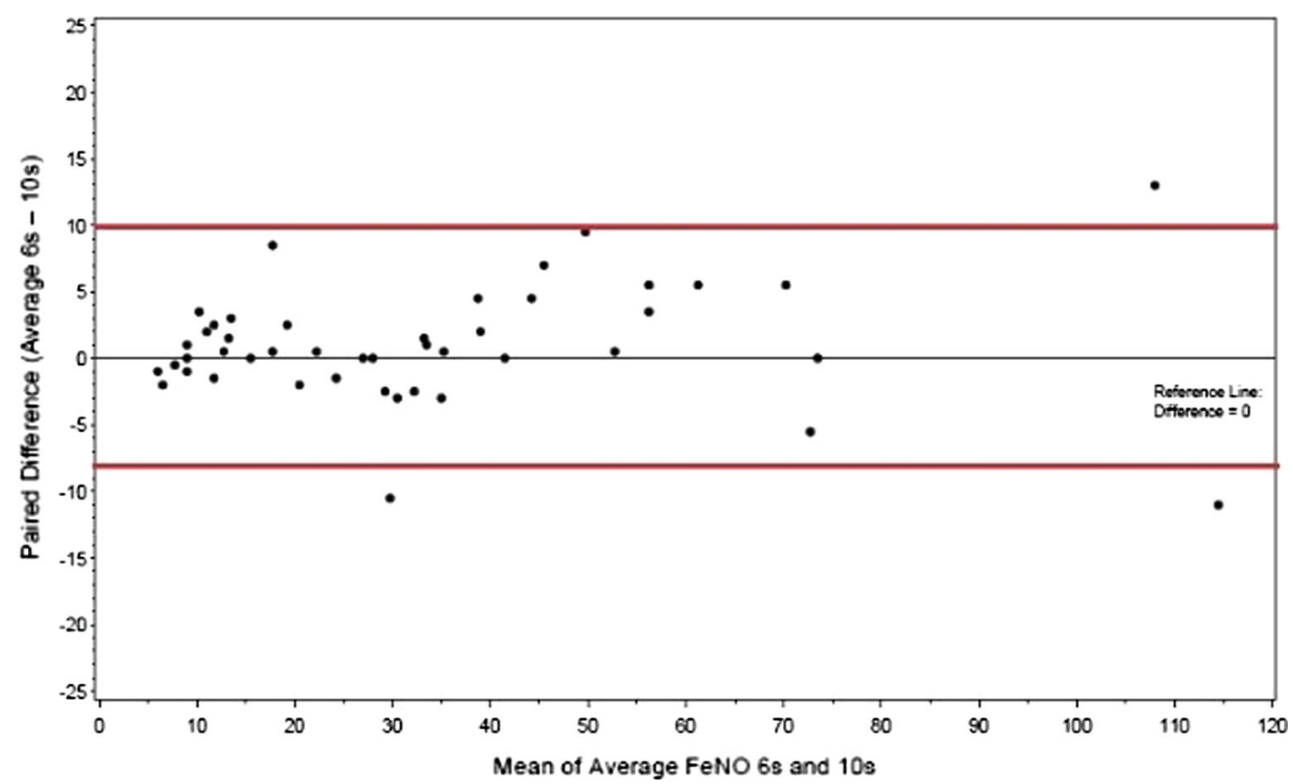

Fig. 3 Bland-Altman plot showing the paired differences in average fractional exhaled nitric oxide results between the 6-s exhalation mode and 10-s exhalation mode in subjects aged 6-10 years (evaluation population for subjects with two observations on both modes)

\section{Assessment of Tolerance Limits}

FeNO values were within the tolerance limits for a high proportion of subjects $(45 / 48 ; 93.8 \%)$ with an exact $95 \%$ CI of $82.8-98.7 \%$ (Table 3 ). Subjects were considered to be within the tolerance limit if they had an absolute difference (average $6 \mathrm{~s}$ FeNO-average $10 \mathrm{~s}$
FeNO) below $10 \mathrm{ppb}$ for subjects with a 10-s mode FeNO value below $35 \mathrm{ppb}$, or an absolute difference below $20 \%$ if their 10-s mode FeNO value was $35 \mathrm{ppb}$ or more. Twenty-nine subjects had a reference FeNO below 35 ppb, all were within tolerance limits and the maximum absolute difference was $8.5 \mathrm{ppb}$. Nineteen had 
Table 3 Assessment of tolerance limits given as absolute percent difference $[(6 s-10 s) / 10 s]$ in average fractional exhaled nitric oxide (evaluation population)

\begin{tabular}{ll}
\hline & $N=\mathbf{4 8}$ \\
\hline Subjects with reference FeNO $<35 \mathrm{ppb}$ & 29 \\
$n$ & \\
Absolute \% difference $[(6 \mathrm{~s}-10 \mathrm{~s}) / 10 \mathrm{~s}]$ in average FeNO & $1.78(1.766)$ \\
Mean $(\mathrm{SD})$ & 1.50 \\
Median & $0.0,8.5$ \\
Min, max & $29 / 29(100.0 \%)(88.1 \%, 100.0 \%)$ \\
Subjects within tolerance limits $(95 \%$ exact CI) & \\
Subjects with reference FeNO $\geq 35 \mathrm{ppb}$ & 19 \\
$n$ & \\
Absolute percent difference $[(6 \mathrm{~s}-10 \mathrm{~s}) / 10 \mathrm{~s}]$ in average FeNO & $10.10(7.902)$ \\
Mean $(\mathrm{SD})$ & 9.17 \\
Median & $0.0,30.0$ \\
Min, max & $16 / 19(84.2 \%)(60.4 \%, 96.6 \%)$ \\
Subjects within tolerance limits $(95 \%$ exact CI) & $45 / 48(93.8 \%)(82.8 \%, 98.7 \%)$ \\
Overall subjects within tolerance limits $(95 \%$ exact CI)
\end{tabular}

$C I$ confidence interval, $\mathrm{FeNO}$ fractional exhaled nitric oxide

a reference FeNO of $35 \mathrm{ppb}$ or more of which $16(84.2 \%)$ were within tolerance limits and the absolute percent differences for the three outside the tolerance limits were close to the limit: $21.1,21.7$, and 30.0\%.

\section{Younger sub-group (4-5-year-olds)}

Ten (83\%) subjects had a valid 6-s mode FeNO result with a mean value of $12.6 \mathrm{ppb}$, of which seven $(70 \%)$ also had a valid 10 -s mode FeNO result with a mean value of $10.6 \mathrm{ppb}$ (Table 4). For these seven subjects, there was good correspondence in FeNO results between the 6 s- and 10-s modes (Fig. 4).

\section{DISCUSSION}

There was good correlation in FeNO values between the 6-s and 10-s modes for the selected age groups and the measurement of FeNO using NIOX VERO ${ }^{\circledR}$ was safe with no AEs or serious injuries reported during the study.
Our results support the agreement and repeatability of the NIOX VERO ${ }^{\circledR}$ device using both exhalation modes in children aged 6-10 years. These data support the viability of the 6-s mode as an alternative option for assessing FeNO in children who are unable to perform the 10-s assessment.

There was a high success rate overall, and particularly with the 6-s mode in the 4 - and 5 -year-olds. While the study was not powered to examine the correlation of both test modes in this sub-group, we were able to plot the correlation and show good agreement in the limited number of observations available and agreed with the findings from the overall study population.

Therefore, successful FeNO measurements can be made in young children aged 4-10 years, enabling physicians to obtain important information to help in the diagnosis and treatment of asthma in this age group. The similarity of observed results 
Table 4 Fractional exhaled nitric oxide results for subjects aged 4-5 years by exhalation time mode (safety population for subjects aged $4-5$ years)

$N=12$

FeNO 6-s mode

Number who successfully completed at least one measurement, $n$ (\%)

Mean FeNO (standard deviation), ppb

Median FeNO, ppb

Minimum, maximum, ppb

FeNO 10-s mode

Number who successfully completed at least one measurement, $n$ (\%)

Mean FeNO (standard deviation), ppb

Median FeNO, ppb

Minimum, maximum

5,19

FeNO fractional exhaled nitric oxide

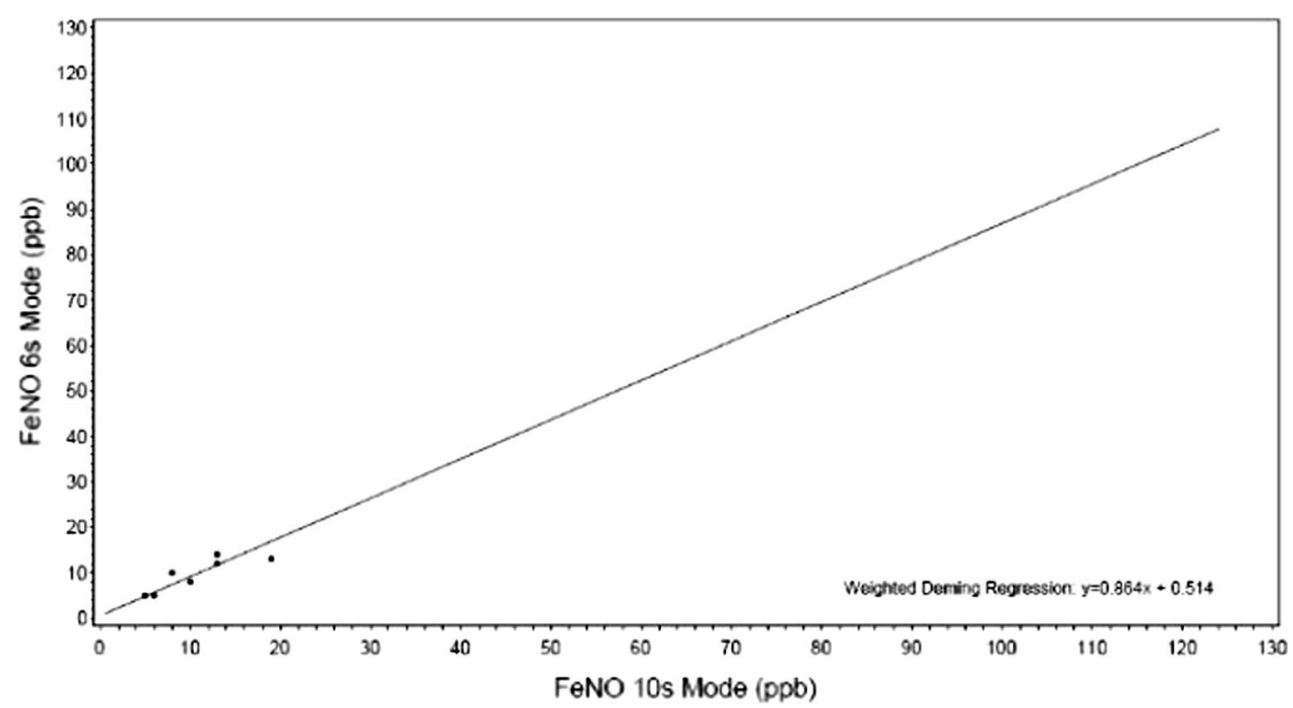

Fig. 4 Weighted Deming regression analysis of observed fractional exhaled nitric oxide (FeNO) results from the seven subjects, aged 4 and 5 years, with valid FeNO measurements in both the 6-s and 10-s exhalation modes (safety population for subjects aged $4-5$ years)

between the modes, the low bias and intra-subject standard deviation, and the high percentage of subjects within the tolerance limits provide evidence of a high degree of agreement between the modes and support the viability of the 6-s mode as an alternative option in assessing FeNO.
Previous studies have shown a correlation between the 6-s and 10-s modes using NIOX $\mathrm{MINO}^{\circledR}$ in children aged $4-17$ years [16-18] for which two studies showed a greater success rate when the 6-s mode was used in younger children $[16,18]$. Other studies have also shown the feasibility of the 6-s mode in 
children (aged 4-18 years) using the NIOX $\mathrm{MINO}^{\circledR}$ device [19-23].

This was a one-visit study simply designed in order to evaluate clinical validation of the NIOX VERO $^{\circledR}$ device using the 6-s and 10-s modes in young children. Study design limitations included the small sample size, though it was adequate to show a strong correlation, and the fact that measurements were taken at one visit, and all subjects were clinically stable. Furthermore, this was a single-center study. Therefore, since FeNO performance quality depends on instruction and training, the data reported here may apply to an experienced team with trained personnel, but not necessarily to broader primary or secondary care settings. The fact that all measurements were done on the same device with the same patient on the same day is considered a strength since it gave a consistent test of the two exhalation modes.

\section{CONCLUSIONS}

We have shown that children aged 6-10 years are able to successfully perform FeNO measurements using the 6-s or 10-s exhalation modes using the NIOX VERO ${ }^{\circledR}$ analyzer. FeNO measurements were repeatable and consistent and with a high degree of agreement between the two modes. Younger children aged 4 and 5 years also successfully performed FeNO measurements using both modes with more success seen using the 6-s mode. Performing FeNO measurements using the shorter exhalation time provides an alternative and feasible option in children who are unable to perform the 10-s measurement. Therefore, successful FeNO measurements can be obtained in young children using the NIOX $\mathrm{VERO}^{\circledR}$ analyzer and provides physicians with important information to aid in the diagnosis and treatment of asthma in this age group.

\section{ACKNOWLEDGEMENTS}

Sponsorship for this study and article processing was funded by Aerocrine Inc (now
Circassia Pharmaceuticals Inc). All named authors meet the criteria for authorship set forth by the International Committee for Medical Journal Editors, take responsibility for the integrity of the work as a whole, and have given final approval to the version to be published. All authors had full access to all of the data in this study and take complete responsibility for the integrity of the data and accuracy of the data analysis. The authors wish to acknowledge the following individuals from Aerocrine Inc for their contributions: Nancy Herje for assistance with the preparation of the protocol and conduct of the study and Chelsea Bradshaw for statistical assistance. All authors were involved in the acquisition, analysis of data, drafting, critical revision of the manuscript, and the final approval of the proof to be published. Editorial assistance in the preparation of this manuscript was provided by Dr. Kathryn White of Cathean Ltd medical writing services. Support for this assistance was funded by Aerocrine Inc.

Disclosures. Glenn Crater was an employee of Aerocrine Inc at the time the study was conducted. At this time, he has no financial interest in the company. Kathy Rickard is an employee of Circassia Pharmaceuticals Inc (formerly Aerocrine Inc) and has no conflict of interest. Jain Neal received a research grant from Aerocrine Inc for the conduct of this study and has received a speaker honorarium from Aerocrine Inc.

Compliance with ethical standards . All procedures followed were in accordance with the ethical standards of the responsible committee on human experimentation (institutional and national) and with the Helsinki Declaration of 1964, as revised in 2013. Informed consent was obtained from each subject's legally authorized representative before being included in the study.

Open Access. This article is distributed under the terms of the Creative Commons Attribution-NonCommercial 4.0 International License (http://creativecommons.org/licenses/ by-nc/4.0/), which permits any noncommercial use, distribution, and reproduction in any 
medium, provided you give appropriate credit to the original author(s) and the source, provide a link to the Creative Commons license, and indicate if changes were made.

\section{REFERENCES}

1. Mahr TA, Malka J, Spahn JD. Inflammometry in pediatric asthma: a review of fractional exhaled nitric oxide in clinical practice. Allergy Asthma Proc. 2013;34:210-9.

2. Smith AD, Cowan JO, Brassett KP, et al. Exhaled nitric oxide: a predictor of steroid response. Am J Respir Crit Care Med. 2005;172:453-9.

3. Zeiger RS, Schatz M, Zhang F, et al. Elevated exhaled nitric oxide is a clinical indicator of future un-controlled asthma in asthmatic patients on inhaled corticosteroids. J Allergy Clin Immunol. 2011;128:412-4.

4. Syk J, Malinovschi A, Johansson G, et al. Anti-inflammatory treatment of atopic asthma guided by exhaled nitric oxide: a randomized, controlled trial. J Allergy Clin Immunol Pract. (Internet). 2013:11. Available from: http:// linkinghub.elsevier.com/retrieve/pii/

S2213219813003528.

5. Powell H, Murphy VE, et al. Management of asthma in pregnancy guided by measurement of fraction of exhaled nitric oxide: a double-blind, randomised controlled trial. Lancet. 2011;378:983-90.

6. Petsky HL, Li AM, Kynaston JA, Turner C, Chang AB. Management based on exhaled nitric oxide levels adjusted for atopy reduces asthma exacerbations in children: a dual centre randomized controlled trial. Pediatr Pulmonol. 2015;50:535-43.

7. Peirsman EJ, Carvelli TJ, Hage PY, et al. Exhaled nitric oxide in childhood allergic asthma management a randomised controlled trial. Pediatr Pulmonol. 2013;n/a.

8. Dinakar C. Exhaled nitric oxide in pediatric asthma. Curr Allergy Asthma Rep. 2009;9:30-7.

9. Pijnenburg MW, Merkus PJ. NO kidding: exhaled nitric oxide fraction in preschool children. Eur Repir J. 2015;45:30-2.

10. Ratnawati R, Thomas PS. Exhaled nitric oxide in paediatric asthma. Chron Respir Dis. 2005;2:163-74.

11. Hanson JR, De Lurgio SA, Williams DD, Dinakar C. Office-based exhaled nitric oxide measurement in children 4 years of age and older. Ann Allergy Asthma Immunol. 2013;11:358-63.

12. American Thoracic Society; European Respiratory Society. ATS/ERS recommendations for standardized procedures for the online and offline measurement of exhaled lower respiratory nitric oxide and nasal nitric oxide. Am J Respir Crit Care Med. 2005;171:912-30.

13. NIOX VERO ${ }^{\circledR}$ user manual. March 2013.

14. Bland JM, Altman DG. Statistical methods for assessing agreement between two methods of clinical measurement. Lancet. 1986;1:307-10.

15. Krouwer JS, Tholen DW, Garber CC, et al. Method comparison and bias estimation using patient samples; approved guideline. 2nd ed. Clinical and Laboratory Standards Institute; 2002. pp. EP9-A2, 22.

16. Ito $\mathrm{Y}$, Adachi $\mathrm{Y}$, Itazawa $\mathrm{T}$, et al. Comparison of exhalation time methods ( $6 \mathrm{sec}$ vs. $10 \mathrm{sec}$ ) of a hand-held exhaled nitric oxide analyser. Pediatr Pulmonol. 2010;45:1005-8.

17. Sardón Prado O, Pérez-Yarza EG, Ruuiz AA, Murua JK, Mintegui Aranburu J, Emparanza Knörr JI. Fracción ecxhalada de óxido nítrico: validactión de la medida con tiempo de espiración de $6 \mathrm{~s}$ con dos analizadores diferentes. An Pedatri (Barc). 2008;69:221-6.

18. Koopman M, Arets HGM, Uiterwaal CSPM, van der Ent CK. Comparing 6- and 10-sec exhalation time in exhaled nitric oxide measurements in children. Pediatr Pulmonol. 2009;44:340-4.

19. Kalliola S, Malmberg P, Rito T, Pelkonen AS, Mäkelä MJ. Can we use portable nitric oxide analyzer in young children? Pediatr Pulmonol. 2011;46:627-31.

20. Chládková J, Havlínová Z, Chyba T, Krcmová I, Chládek J. Analysis of single-breath profiles of exhaled nitric oxide in children with allergy and asthma: guideline-derived plateau concentrations compared to results of automatic evaluation by two analyzers. J Asthma. 2008;45:820-6.

21. Arnold DH, Gebretsadik T, Abramo TJ, Hartert TV. Noninvasive testing of lung function and inflammation in pediatric patients with acute asthma exacerbations. J Asthma. 2012;49:29-35.

22. Baptist AP, Shah B, Wang Y, Ager J, Badr MS. Exhaled nitric oxide measurements in hospitalized children with asthma. J Asthma. 2008;45:670-4.

23. Janahi I, Saadoon A, Tuffaha A, Panneerselvam B. Effects of age, gender, and environment exposures on exhaled nitric oxide level I healthy $12-18$ years Qatari children. Ann Thorac Med. 2012;7:98-103. 